\title{
Solunumsal Yoğun Bakım Ünitesinde Florokinolon Kullanımının Hastane Kökenli MRSA Enfeksiyonu Gelişimine ve Prognoza Etkisi
}

\section{The Effect of Fluoroquinolone Use in the Respiratory Intensive Care Unit on the Development of Hospital-Acquired MRSA Infection and Its Prognosis}

\author{
Nigar DiRiCAN ${ }^{1}$, A. Tolga ÖZ², Hüsnü PULLUKÇU ${ }^{3}$, Şöhret AYDEMiR ${ }^{4}$, Feza BACAKOĞLU ${ }^{5}$ \\ ${ }^{1}$ Süleyman Demirel Üniversitesi Tıp Fakültesi, Göğüs Hastalıkları Anabilim Dalı, Isparta. \\ ${ }^{1}$ Suleyman Demirel University Faculty of Medicine, Department of Chest Diseases, Isparta, Turkey. \\ ${ }^{2}$ İzmir Üniversitesi Tıp Fakültesi, Göğüs Hastalıkları Anabilim Dalı, İzmir. \\ ${ }^{2}$ Izmir University Faculty of Medicine, Department of Chest Diseases, Izmir, Turkey. \\ ${ }^{3}$ Ege Üniversitesi Tıp Fakültesi, Enfeksiyon Hastalıkları ve Klinik Mikrobiyoloji Anabilim Dalı, İzmir. \\ ${ }^{3}$ Ege University Faculty of Medicine, Department of Infectious Diseases and Clinical Microbiology, Izmir, Turkey. \\ ${ }^{4}$ Ege Üniversitesi Tıp Fakültesi, Tıbbi Mikrobiyoloji Anabilim Dalı, İzmir. \\ ${ }^{4}$ Ege University Faculty of Medicine, Department of Medical Microbiology, Izmir, Turkey. \\ ${ }^{5}$ Ege Üniversitesi Tıp Fakültesi, Göğüs Hastalıkları Anabilim Dalı, İzmir. \\ ${ }^{5}$ Ege University Faculty of Medicine, Department of Chest Diseases, Izmir, Turkey.
}

\section{ÖZET}

Metisiline dirençli Staphylococcus aureus (MRSA), dünya çapında yaygın, ciddi bir halk sağlığı sorunu haline gelmiştir. Bazı çalışmalarda, MRSA enfeksiyonlarının yüksek oranda görülmesiyle uzun süreli florokinolon (FQ) kullanımı arasında bir ilişki olabileceği belirtilmektedir. Bu çalışmada, solunumsal yoğun bakım ünitesi (YBÜ)’nde FQ kullanımının, hastane kökenli MRSA enfeksiyonu gelişimi ve mortalite üzerine etkisinin araştırılması amaçlanmıştır. Tek merkez deneyimi olarak, iki yıl boyunca solunumsal YBÜ'de izlenen hastaların klinik ve laboratuvar verileri retrospektif olarak değerlendirilmiştir. FQ kullanımının MRSA enfeksiyonu gelişimiyle olan ilişkisi korelasyon analizi, mortalite ile olan ilişkisi de regresyon analizi kullanılarak araştııımıştır. Çalışmaya dahil edilen 302 hastanın 93 (\%30.7)'ünde FQ tedavisi kullanıldığı belirlenmiş; yaş ortalamaları $71.1 \pm 12.5$ yıl olan bu hastaların 64'ünün erkek olduğu gözlenmiştir. İzlem sırasında hastaların \%11.9 (36/302)'unda MRSA enfeksiyonu gelişmiş; FQ tedavisi uygulanan hastalarda ise MRSA enfeksiyonu görülme oranı \%15.1 (14/93) olarak saptanmıştır. FQ tedavisi alan ve MRSA enfeksiyonu gelişen 14 hastanın sekizinde ventilatörle ilişkili pnömoni (VIP), altısında sekonder bakteriyemi belirlenmiştir. FQ kullanımıyla MRSA enfeksiyonu gelişimi arasında pozitif bir korelasyon saptanmakla Çünür 32260, Isparta, Türkiye. Tel (Phone): +90 246211 3236, E-posta (E-mail): nigardirican@yahoo.com 
birlikte, bu durum istatistiksel olarak anlamlı bulunmamışı ı $[\mathrm{P}=0.521$ (Spearman), $\mathrm{p}=0.037$ (Pearson)]. Çalışmada ayrıca, FQ kullanılan hastaların YBÜ'ye yatışı sırasında bakılan CRP ve lökosit düzeyleri için sınır değerleri belirlenmiş (sırasıyla; $7.85 \mathrm{mg} / \mathrm{L}$ ve 7650 hücre $/ \mathrm{mm}^{3}$ ) ve bu değerlerin MRSA enfeksiyonu gelişimiyle ilişkisi araştııılmıştır. Buna göre, yüksek lökosit düzeyleri (> 7650/mm $\left.{ }^{3}\right)$ ile MRSA enfeksiyonu gelişimi arasında pozitif ve anlamlı bir ilişki saptanırken ( $P=0.017, p=0.246)$, CRP düzeyleriyle anlamlı bir iliş̧i $(P=0.121, p=0.178)$ gözlenmemiştir. FQ kullanılan hastalarda mortalite oranı \%42 (39/93) olarak izlenmiş; malignite varlığı, son altı ay içinde hastaneye yatış hikayesi ve hastane enfeksiyonu gelişiminin, mortalite riskini artırdığı (sırasıyla; $p=0.020, p=0.038$ ve $p=0.024$ ) saptanmıştır. Yapılan çok değişkenli analiz sonucunda FQ kullanılan hastalarda, malignite (OR: 2.280, $\mathrm{p}=0.002$ ), re-entübasyon uygulamaları (OR: 4.071, $p=0.005$ ), ViP gelişimi (OR: 5.097, $p=0.009$ ) ve 7 günden uzun süre FQ kullanımı (OR: $3.63, p=0.003$ ) olmak üzere mortalite ile ilişkili dört bağımsız risk faktörü tanımlanmıştır. Sonuç olarak verilerimiz, YBÜ'de yatan hastalarda florokinolon kullanımının, hastane kaynaklı MRSA enfeksiyonu gelişimini anlamlı olarak artırmadığını ve $>7$ gün FQ kullanımının, mortaliteyi etkileyen bağımsız bir risk faktörü olduğunu göstermiş; ayrıca YBÜ'ye yatış anındaki yüksek lökosit düzeylerinin, MRSA enfeksiyonu gelişimi açısından bir öngörü belirteci olabileceğini düşündürmüştür.

Anahtar sözcükler: Yoğun bakım ünitesi; hastane enfeksiyonu; florokinolon; metisiline dirençli Staphylococcus aureus; MRSA; risk faktörü.

\section{ABSTRACT}

Methicillin-resistant Staphylococcus aureus (MRSA) which exhibits a worldwide spread, has become a serious public health problem. There are several studies indicating that there may be a relationship between the high rate of MRSA infections and long-term use of fluoroquinolones. The aim of this study was to investigate the effect of fluoroquinolone (FQ) use in the respiratory intensive care unit (ICU) on the development of the hospital-acquired MRSA infection and mortality. This was a single center experience, in which the clinical and laboratory data of the patients who were hospitalized in the respiratory ICU for two years, were retrospectively evaluated. The relationship between FQ use and the development of MRSA infection was evaluated with correlation analysis, and its relationship with the mortality was evaluated with regression analysis. A total of 302 patients were included in the study and 93 (30.7\%) of them were found to be treated with FQs. Sixty-four of those 93 patients were male and the mean age was $71.1 \pm 12.5$ years. During the follow-up, MRSA infections developed in 11.9\% (36/302) of the patients, and the rate of MRSA infection in FQ using patients was 15.1\% (14/93), of them eight were ventilator-associated pneumonia (VAP) and six were secondary bacteremia. Although a positive correlation was found between FQ use and the development of MRSA infection, it was not statistically significant $[\mathrm{P}=0.521$ (Spearman), $\mathrm{p}=0.037$ (Pearson)]. In addition cut-off values for CRP and leukocyte counts, which were checked when a patient with FQ use admitted to the ICU, were determined as 7.85 $\mathrm{mg} / \mathrm{L}$ and $7.650 / \mathrm{mm}^{3}$, respectively. The analysis of the relationship between CRP, leukocyte counts and the development of MRSA infection revealed a statistically significant positive relationship between high leukocyte levels $\left(>7.650 / \mathrm{mm}^{3}\right)$ and the development of MRSA infection $(P=0.017, p=0.246)$, but no such relationship for the CRP levels $(P=0.121, p=0.178)$. The mortality rate in patients with $F Q$ use was found as $42 \%$ (39/93), and it was determined that malignancy, history of admission to hospital in the previous six months and the presence of a hospital-acquired infection increased the risk of mortality $(p=0.020, p=0.038$ and $p=0.024$, respectively). In the multivariate analysis, four independent risk factors related to the mortality in patients under FQ treatment were determined, namely malignancy (OR: 2.280, $p=0.002$ ), re-intubation practices (OR: 4.071, $p=0.005)$, VAP (OR: 5.097, $p=0.009$ ) and the use of $F Q>7$ days (OR: 3.63, $p=0.003$ ). In conclusion, our data indicated that the use of FQs in the ICU did not increase the development of hospital-acquired MRSA infection significantly, and FQ use for more than seven days was an independent risk factor for mortality. Additionally, it was thought that high leukocyte counts might be a predictive marker for the development of MRSA infection.

Key words: Intensive care unit; nosocomial infection; fluoroquinolone; methicillin-resistant Staphylococcus aureus; MRSA; risk factor. 


\section{Gíriş}

Antimikrobiyal ilaçlara dirençli mikroorganizmaların özellikle yoğun bakım ünitelerinde giderek yaygınlaşması, önemli bir sağlık sorunu haline gelmiştir ${ }^{1}$. Yoğun bakımlarda saptanan en önemli nozokomiyal patojenlerden biri, metisiline dirençli Staphylococcus aureus (MRSA)'dur. Yoğun bakımda çok ilaca dirençli (MDR) patojenlerle gelişen enfeksiyonlar için risk faktörleri arasında; ileri yaş, eşlik eden hastalıklar (maligniteler, böbrek yetmezliği, diyabet vb.), yoğun bakım ünitesi (YBÜ)'ne alınmadan önce uzun süreli hastanede kalış öyküsü, invazif girişimsel cihazların varlı̆̆ı (foley idrar kateteri, santral venöz kateterler, endotrakeal tüpler vb.), yeni geçirilmiş cerrahi veya invazif işlemler ve sağlık personeliyle hastadan hastaya patojenlerin taşınması sayılabilir ${ }^{2,3}$. MDR patojenlerle enfeksiyon gelişimiyle, antibiyotik özellikle de sefalosporin ve florokinolon (FQ) kullanımı arasında oldukça kuvvetli ilişki bulunmuştur ${ }^{4-6}$. Ayrıca, FQ kullanım süresiyle antibiyotik direnci gelişimi arasında da ilişki saptanmıştır ${ }^{7}$. MDR patojenler ile YBÜ'de gelişen enfeksiyonlarda; sağlık harcamaları ve mortalite oranlarında artma, hastanede kalış süresinde uzama gözlenmiştir ${ }^{8}$. Ayrıca, YBÜ'de ampirik FQ kullanımının, mortaliteyi de artırdığı gösterilmiştir ${ }^{9}$. Bu çalışmanın amacı, solunumsal YBÜ’de yatan hastalarda FQ kullanımının, hastane kökenli MRSA enfeksiyonu gelişimi ve mortaliteyle olan ilişkisinin araştııımasıdır.

\section{GEREÇ ve YÖNTEM}

Çalışmada, Ege Üniversitesi Tıp Fakültesi, Göğüs Hastalıkları Anabilim Dalına ait sekiz yataklı yoğun bakım ünitesinde iki yıl boyunca izlenen 302 hastanın verileri retrospektif olarak değerlendirildi. Hastaların, altta yatan hastalık ve immün süpresyon durumları, son üç ay içerisinde sistemik kortikosteroid kullanımı, son altı ay içerisinde geçirilen cerrahi ve diğer invazif işlemleri, başvurudaki APACHE II skoru, $\mathrm{PaO}_{2} / \mathrm{FiO}_{2}$ oranı, sepsis ve organ yetmezlikleri, klinik ve laboratuvar bulguları ile FQ kullanım bilgileri kaydedildi. Ayrıca YBÜ izlemlerinde; kateter, entübasyon, trakeotomi ve invazif mekanik ventilasyon uygulamaları, parenteral beslenme, fiberoptik bronkoskop kullanımı, peptik ülser proflaksisi, gelişen enfeksiyonlar ve antibiyotik kullanımlarılla YBÜ'de kalış süreleri ve sağkalım bilgileri elde edildi.

İstatistiksel analizlerde; kategorik değişkenler için ki-kare ve Fisher'in kesin ki-kare testleri, parametrik ölçümler için Student's t-testi kullanıldı. İstatistiksel anlamlıık için $p<$ 0.05 değeri kabul edildi. CRP ve lökosit düzeylerinin sınır değerlerinin belirlenmesi için ROC eğrisi analizi uygulandı. FQ kullanılan hastalarda; MRSA enfeksiyonu gelişimi ile risk faktörleri arasındaki ilişkiyi saptamak için Spearman korelasyon analizi, mortaliteyle ilişkili risk faktörlerini belirlemek için ise Cox regresyon analizi kullanıldı.

\section{BULGULAR}

Çalışmamızda, solunumsal YBÜ'de iki yıl boyunca izlenen 302 hastanın retrospektif değerlendirilmesi sonunda 93 hastanın FQ kullandığı tespit edilmiştir. Bu hastaların 64'ü erkek, $29^{\prime}$ u kadın olup, yaş ortalamaları $71.1 \pm 12.5$ yıldır. Hastaların $81^{\prime}$ inin levoflok- 
sasin, 12'sinin ise moksifloksasin kullandığı belirlenmiş; FQ uygulamasının 80 hastada parenteral, 13 hastada oral yolla yapıldığı izlenmiştir. Ortalama FQ kullanım süresi $8.1 \pm$ 4.2 gün olarak bulunmuştur. FLQ kullanılan hastaların demografik özellikleri Tablo I'de özetlenmiştir.

Florokinolon kullanılan 93 hastanın 8'inde ventilatörle ilişkili pnömoni (VIP), 6'sında ViP'in yanı sıra sekonder bakteriyemi olmak üzere toplam 14 (\%15.1) hastada MRSA'ya bağlı hastane enfeksiyonu geliştiği belirlenmiştir. Ayrıca, FQ tedavisi alan hastaların 21'i ViP’li olmak üzere toplam 26 (\%28)'sında, MRSA dışı mikroorganizmalara bağlı (11

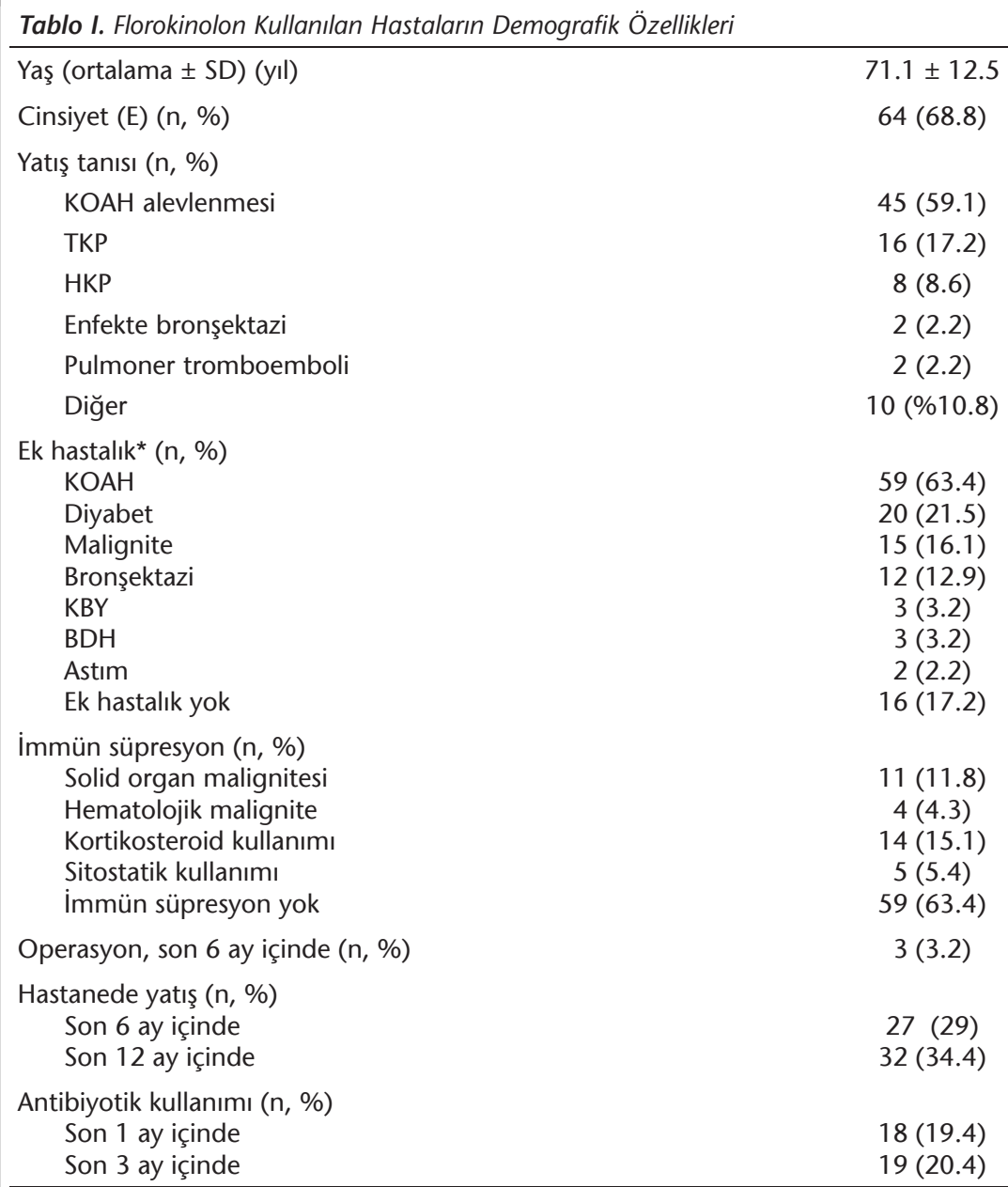

Son 6 ay içinde

Antibiyotik kullanımı (n, \%)

Son 1 ay içinde

* 30 olguda (\%32.2) birden fazla ek hastalık saptanmıştır.

E: Erkek; KOAH: Kronik obstrüktüf akciğer hastalığı; TKP: Toplum kaynaklı pnömoni; HKP: Hastane kaynaklı pnömoni; KBY: Kronik böbrek yetmezliği; BDH: Bağ dokusu hastalığı. 
Acinetobacter, 4 Pseudomonas aeruginosa, 3 Acinetobacter + P.aeruginosa, 3 Enterococcus spp., 1 Enterobacter spp. + Acinetobacter, 1 Escherichia coli, 1 Acinetobacter + E.coli, 1 Chryseomonas luteola, 1 Candida spp.) hastane enfeksiyonu geliştiği saptanmıştır.

Florokinolon kullanan hastaların 15 (\%16.1)'inde, son bir ay içinde diğer antibiyotiklerin de [Nonpsödomonal sefalosporin (7), amoksisilin-klavulonat (4), piperasilin-tazobaktam (2), antipsödomonal sefalosporin (1), teikoplanin (1)] kullanıldığı görülmüş ve bu hastalarla MRSA enfeksiyonu gelişimi arasında pozitif bir ilişki bulunmuştur $(P=0.002$, $\mathrm{p}=0.322$ ) (Tablo II).

Florokinolon kullanan hastaların YBÜ'ye yatışları sırasında bakılan CRP ve lökosit düzeyleri için sınır değerleri sırasıyla $7.85 \mathrm{mg} / \mathrm{L}$ ve 7650 hücre $/ \mathrm{mm}^{3}$ olarak belirlenmiştir. Buna göre; yüksek lökosit değerine (> 7650 hücre $/ \mathrm{mm}^{3}$ ) sahip olan hastalar ile MRSA enfeksiyonu gelişimi arasında anlamlı ilişki saptanırken $(P=0.017, p=0.246)$, yüksek CRP değerleri (> $7.85 \mathrm{mg} / \mathrm{L}$ ) ile MRSA enfeksiyonu gelişimi arasındaki ilişki anlamlı bulunmamıştır $(P=0.121, p=0.178)$.

Florokinolon kullanan hastaların prognozu değerlendirildiğinde mortalite oranının \%42 (39/93) olduğu görülmüştür. Mortalite oranları; malignitesi olan hastalarda (\%92.9'a karşı \%38.9, $\mathrm{p}=0.020)$, son 6 ayda hastanede yatış öyküsü bulunanlarda (\%59.3'e karşı \%34.8, p=0.038) ve izleminde MRSA dışı mikroorganizmalara bağlı hastane enfeksiyonu gelişenlerde (\%60'a karşı \%33.3, $\mathrm{p}=0.024)$ daha yüksek bulunmuştur. FQ kullanılan hastalarda mortaliteye etki eden risk faktörleri önce tek değişkenli analizle

\begin{tabular}{|c|c|c|}
\hline Risk faktörleri & $P^{*}$ & $p^{*}$ \\
\hline Yaş & 0.048 & 0.206 \\
\hline Yoğun bakım yatış süresi & $<0.001$ & 0.579 \\
\hline Diyabet & 0.004 & 0.294 \\
\hline Operasyon (son 6 ay içinde) & 0.028 & 0.229 \\
\hline İlave başka grup antibiyotik kullanımı (son 1 ay içinde) & $<0.001$ & 0.532 \\
\hline Tip II solunum yetmezliği & 0.016 & 0.250 \\
\hline Santral venöz kateter & 0.028 & 0.229 \\
\hline Total parenteral beslenme & 0.004 & 0.298 \\
\hline Entübasyon & $<0.001$ & 0.376 \\
\hline Re-entübasyon & 0.03 & 0.395 \\
\hline Trakeostomi & $<0.001$ & 0.450 \\
\hline Nozokomiyal enfeksiyon & $<0.001$ & 0.507 \\
\hline Lökosit sayısı ${ }^{\star *}>7650 / \mathrm{mm}^{3}$ & 0.017 & 0.246 \\
\hline
\end{tabular}


belirlenmiş (Tablo III); daha sonra sonuçlar çok değişkenli analizle değerlendirildiğinde; malignite tanısı bulunması, re-entübasyon yapılması, VIP gelişimi ve $>7$ gün FQ kullanımı, mortaliteyle ilişkili bağımsız risk faktörleri olarak saptanmıştır (Tablo IV).

Hastane kaynaklı MRSA enfeksiyonu gelişen 36 hastanın demografik özellikleri Tablo V'te, enfeksiyon için risk faktörleri ise Tablo $\mathrm{VI}^{\prime}$ da gösterilmiştir. Hastaların hiçbirinde, son 6 ay içinde MRSA enfeksiyonu ve glikopeptid kullanımı öyküsü bulunmadığı görülmüştür. Hastaların YBÜ'ye yatışı sırasında ortalama APACHE II skoru $24.8 \pm 6.2$ ve $\mathrm{PaO}_{2} / \mathrm{FiO}_{2}$ oranı $173.3 \pm 72.9$ olarak hesaplanmıştır.

Tablo III. Florokinolon Kullanılan Hastalarda Mortaliteye Etki Eden Risk Faktörlerinin Tek Değişkenli Analiz Ile Değerlendirilmesi

\begin{tabular}{lcccc}
\hline Risk faktörleri & Sayı & $\% 95 \mathrm{Cl}$ & OR & $\mathbf{p}$ \\
\hline Erkek cinsiyet & 64 & $0.779-2.877$ & 1.49 & 0.234 \\
$>$ 65 yaş & 69 & $0.423-2.07$ & 0.93 & 0.872 \\
Diyabet & 20 & $0.383-1.513$ & 0.761 & 0.436 \\
Malignite & 15 & $1.106-3.450$ & 1.218 & 0.001 \\
Kronik böbrek yetmezliği & 3 & $0.067-1.233$ & 0.287 & 0.093 \\
Operasyon (son 3 ay içinde) & 3 & $0.153-1.709$ & 0.511 & 0.274 \\
Hastanede yatış (son 3 ay içinde) & 18 & $0.239-0.953$ & 0.478 & 0.036 \\
Tip Il solunum yetmezliği & 65 & $1.716-7.123$ & 3.49 & 0.001 \\
Santral venöz kateter & 9 & $0.377-1.93$ & 0.854 & 0.704 \\
Parenteral beslenme & 53 & $0.998-3.758$ & 1.93 & 0.051 \\
Fiberoptik bronkoskopi & 10 & $0.459-2.29$ & 1.025 & 0.95 \\
Entübasyon & 57 & $0.943-4.494$ & 2.059 & 0.070 \\
Re-entübasyon & 18 & $1.333-7.076$ & 3.071 & 0.008 \\
Trakeostomi & 8 & $1.00-6.971$ & 2.64 & 0.050 \\
Ventilatörle ilişkili pnömoni & 14 & $1.430-10.822$ & 3.934 & 0.008 \\
Kinolon kullanım süresi (> 7 gün) & 43 & $1.816-8.822$ & 4.003 & 0.001 \\
CRP (> 7.85) & 42 & $0.196-0.906$ & 0.422 & 0.027 \\
Lökosit (> 7650/mm ${ }^{3}$ ) & 78 & $0.250-1.326$ & 0.576 & 0.195 \\
\hline Cl: Confidence interval, OR: Odds Ratio. & & & & \\
\hline
\end{tabular}

\begin{tabular}{|c|c|c|c|}
\hline Risk faktörleri & $\% 95 \mathrm{Cl}$ & OR & $\mathrm{p}$ \\
\hline Malignite & $1.123-4.650$ & 2.280 & 0.002 \\
\hline Re-entübasyon & $1.525-10.850$ & 4.071 & 0.005 \\
\hline Ventilatörle ilişkili pnömoni & $1.504-17.276$ & 5.097 & 0.009 \\
\hline Kinolon kullanım süresi (> 7 gün) & $1.593-8.620$ & 3.63 & 0.003 \\
\hline
\end{tabular}




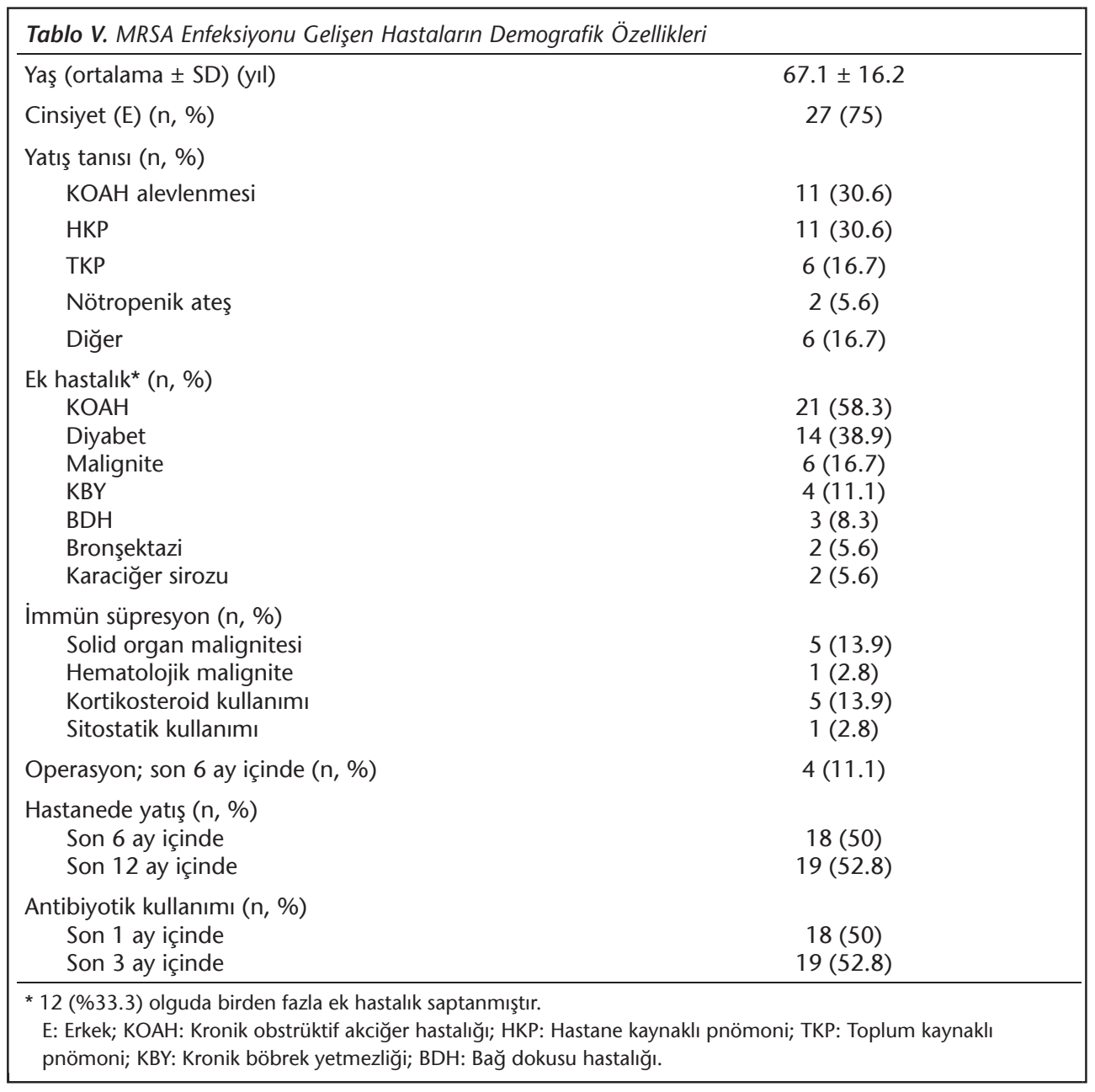

Tablo VI. MRSA Enfeksiyonu Için Risk Faktörleri

\begin{tabular}{ll|}
\hline Risk faktörleri & Sayı (\%) \\
\hline Kateterizasyon & $17(47.2)$ \\
Parenteral beslenme & $24(66.7)$ \\
Sistemik kortikosteroid kullanımı & $21(58.3)$ \\
Florokinolon tedavisi & $14(38.9)$ \\
\hline
\end{tabular}


MRSA'nın en sık endotrakeal aspirat (ETA; $n=21)$ örneklerinden izole edildiği izlenmiş; bunu sırasıyla mini-bronkoalveoler lavaj (BAL; $n=5)$, kan $(n=3), B A L(n=2), E T A+$ mini$\operatorname{BAL}(n=2), E T A+B A L+$ kan $(n=1), B A L+$ kan + plevra $(n=1)$ ve ETA + mini-BAL + kan + plevra $(n=1)$ izlemiştir.

Hastaların 33 (\%91.7)'ünde MRSA'ya bağlı ViP, 6 (\%16.7)'sında bakteriyemi (3'ünde ViP'e sekonder) saptanmıştır. MRSA'ya bağlı hastane enfeksiyonu gelişen 36 olgunun 22 (\%61.1)'sinde bakteriyolojik eradikasyon sağlandığı belirlenmiştir.

Yoğun bakımda enfeksiyon gelişimi için belirlenen risk faktörleri, MRSA enfeksiyonu gelişen hastalarda daha yüksek oranda bulunmakla beraber, aradaki farkın istatistiksel olarak anlamlı olmadığı görülmüştür ( $p>0.05$, Tablo VII). MRSA enfeksiyonu gelişen hastaların 21 (\%58.3)'inde medyan $10.9 \pm 5.5$ gün antipsödomonal sefalosporin, 14 (\%38.9)'ünde ise medyan $7.6 \pm 8.8$ gün FQ (11 hastada levofloksasin, 2 hastada siprofloksasin, 1 hastada moksifloksasin) kullanımı olduğu saptanmıştır. FQ kullanımının MRSA enfeksiyonu gelişimi için risk faktörü olup olmadığını değerlendirmek için; önce, MRSA enfeksiyonu gelişen ve gelişmeyen hastalarda FQ kullanımı karşılaştırılmıştır. Buna göre FQ kullanımı, MRSA enfeksiyonu gelişen hastalarda (14/36; \%38.9), gelişmeyen hastalardan (79/266; \%29.7) daha yüksek bulunmuştur ( $p=0.262)$. FQ kullanan ve kullanmayan hastalarda MRSA enfeksiyonu gelişme oranları karşılaştırıldığında ise MRSA enfeksiyonu gelişme oranı, FQ kullanılan hastalarda (14/93; \%15.1), kullanılmayan hastalardan (22/209; \%10.5) daha yüksek olarak saptanmıştır $(p=0.262)$. Ancak aradaki farklar istatistiksel olarak anlamlı olmadığından, hastanede FQ kullanımının, MRSA enfeksiyonu gelişimini anlamlı olarak artırmadığı sonucuna varılmıştır.

Tablo VII. Hastane Kaynaklı MRSA Enfeksiyonu Gelişme Durumuna Göre Risk Faktörlerinin Karşılaştırılması

\begin{tabular}{|c|c|c|}
\hline \multirow[b]{2}{*}{ Risk faktörleri } & \multicolumn{2}{|c|}{ MRSA enfeksiyonu } \\
\hline & $\operatorname{Var}(n=36)$ & Yok $(n=266)$ \\
\hline Yaş (ortalama \pm SD) (yıl) & $67.1 \pm 16.2$ & $65.9 \pm 15.9$ \\
\hline Cinsiyet (E) (n, \%) & $27(75.0)$ & $180(67.7)$ \\
\hline Hastanede yatış öyküsü; son 12 ay içinde (n, \%) & $19(52.8)$ & $111(41.7)$ \\
\hline $\begin{array}{l}\text { Ek hastalık }(n, \%) \\
\text { Diyabet }\end{array}$ & $\begin{array}{l}32(88.9) \\
14(38.9)\end{array}$ & $\begin{array}{l}231(86.8) \\
68(25.6)\end{array}$ \\
\hline Antibiyotik kullanımı; son 3 ay içinde (n, \%) & $19(52.8)$ & $102(38.3)$ \\
\hline Hastalık şiddeti-APACHE II (ortalama \pm SD) & $24.8 \pm 6.2$ & $23.4 \pm 5.3$ \\
\hline Kateterizasyon (n, \%) & $17(47.2)$ & $102(38.3)$ \\
\hline Parenteral beslenme (n, \%) & $24(66.7)$ & $120(45.1)$ \\
\hline Sistemik kortikosteroid kullanımı (n, \%) & $21(58.3)$ & $94(35.3)$ \\
\hline Florokinolon tedavisi (n, \%) & $14(38.9)$ & $79(29.7)$ \\
\hline
\end{tabular}


Hastanede MRSA enfeksiyonu gelişen hastalarda mortalite oranı \%75 (27/36) olarak saptanmış; mortaliteyle demografik özellikler ve risk faktörleri arasında istatistiksel olarak anlamlı ilişki belirlenmemiştir.

\section{TARTIŞMA}

Göğüs hastalıkları solunumsal YBÜ'de, FQ kullanımıyla hastane kaynaklı MRSA enfeksiyonu gelişimi arasındaki ilişkinin retrospektif olarak değerlendirildiği tek merkezli bu çalışmada; YBÜ'de FQ kullanımının, hastane kaynaklı MRSA enfeksiyonu gelişimini anlamlı olarak artırmadığı tespit edilmiştir. Ancak bu hasta grubunda, YBÜ'ye yatış sırasında saptanan lökosit düzeyi yüksekliğinin MRSA enfeksiyonu gelişimini öngören bir belirteç, yedi günü aşan FQ kullanımının da mortalite için bağımsız bir risk faktörü olduğu sonucuna varılmıştır.

Yeni nesil florokinolonlar, gram-pozitif bakterilerin tedavisinde etkili olacakları düşünülerek, 1990'lı yılların ikinci yarısında yoğun olarak kullanılmaya başlanmıştır. Ancak "SENTRY- Antimicrobial Surveillance" programında alınan birçok kan kültüründe, stafilokokların yeni kuşak florokinolonlara dirençli olduğu gösterilmiştir ${ }^{11}$. Metisiline duyarlı S.aureus (MSSA) ve MRSA ile kolonize olgular karşılaştırıldığında; hastaya uygulanan antibiyotik sayısı ve tedavi süresi ile MRSA enfeksiyonu gelişme riski arasında anlamlı ilişki bulunmuştur ${ }^{12}$. Antibiyotik grupları içinde sefalosporinler ve florokinolonların MRSA kolonizasyonunu kolaylaştırdığı, bu antibiyotiklerin kullanımı arttıkça MRSA kolonizasyon ve enfeksiyon insidansının arttığı gözlenmiştir ${ }^{12}$. Özellikle FQ kullanımı ve uzun kullanım süresinin, MRSA enfeksiyonu gelişimi için bağımsız risk faktörü olduğu belirtilmektedir ${ }^{12,13}$. Lafaurie ve arkadaşlarının ${ }^{14}$ çalışmasında, florokinolon kullanımının kısıtlandığı 10 yıllık bir süreçte, MRSA enfeksiyonu gelişiminde de azalma olduğu ifade edilmektedir. Schneider-Lindner ve arkadaşları ${ }^{15}$, 1981 MRSA hastasını içeren çalışmalarında, birden fazla antibiyotik kullanımıyla MRSA enfeksiyon riskinin arttığını göstermişlerdir. Bizim çalışmamızda ise, FQ kullanımı ile MRSA enfeksiyonu gelişimi arasında düşük düzeyde pozitif ilişki saptanmış, ancak bu ilişki istatistiksel olarak anlamlı düzeye ulaşmamıştır $(P=0.521, p=0.037)$. Bu sonuç, hasta sayımızın az olmasına bağlı olabilir. Öte yandan çalışmamızda, Schneider-Lindner ve arkadaşlarının ${ }^{15}$ verilerine benzer şekilde, hastaneye yatışından itibaren FQ kullanan hastalar içerisinde, son bir ayda başka bir grup antibiyotik kullananlar incelendiğinde; FQ ile birlikte başka antibiyotiklerin kullanımıyla MRSA enfeksiyonu gelişimi arasında pozitif ve anlamlı bir ilişki bulunmuştur ( $P=$ $0.002, p=0.322)$.

Yüksek lökosit düzeylerinin, inflamasyon göstergesi olarak bir çok klinik durumla ilişkili ve prognostik değeri olduğu önceki çalışmalarda gösterilmiştir ${ }^{16,17}$. Ayrıca, enfeksiyon hastalıkları sırasında da lökosit sayısında artış olduğu bilinmektedir ${ }^{18,19}$. Miedzybrodzki ve arkadaşları ${ }^{20}$ MRSA enfeksiyonuna karşı kullanılan antibakteriyel tedaviyle lökosit sayısında azalma saptadıklarını rapor etmişlerdir. Bir hayvan modelinde de, BALB/c farelere intraperitoneal olarak MRSA enjeksiyonu sonrası, periferik nötrofil sayısında artış olduğu 
görülmüştür ${ }^{21}$. İnflamasyona yanıt olarak, nötrofillerin kemik iliğinde üretimi ve periferik kana salınımı hızla artarken lenfosit sayısı azalmaktadır ${ }^{22,23}$. Lökosit sayısının iki temel bileşeni olan nötrofil ve lenfosit sayılarında gerçekleşen bu değişikliklerle, lökosit sayısının normal duruma göre artacağı düşünülebilir. Bizim çalışmamızda da, FQ tedavisi uygulanan hastalarda, yatıştaki yüksek lökosit düzeyleriyle izlemde MRSA enfeksiyonu gelişimi arasında anlamlı bir ilişki saptanmıştır. YBÜ'de takip edilen hastalarda total parenteral nütrisyon uygulaması, diyabet varlığı, yoğun bakımda kalış süresi, entübasyon ve santral venöz kateter uygulamalarının, MRSA ve diğer patojenlere bağlı nozokomiyal enfeksiyonları artırdığı gösterilmiştiı ${ }^{24-26}$. Çalışmamızda da FQ kullanılan hastalarda benzer risk faktörleri ile MRSA enfeksiyonu gelişimi arasında ilişki saptanmıştır.

Çalışmamızda, FQ kullanılan hastalardan malignitesi olanlar, son altı ay içerisinde hastaneye yatış öyküsü bulunanlar ve diğer mikroorganizmalara bağlı hastane enfeksiyonu gelişenlerde mortalite oranları daha yüksek bulunmuştur. Yoğun bakımda FQ kullanımının mortaliteyi artırması; dirençli mikroorganizmalara bağlı hastane enfeksiyonu sıklığının artması, yoğun bakımda kalış sürelerin uzaması ve ilaca bağlı QT uzaması gibi kardiyak yan etkilerden kaynaklanabilmektedir ${ }^{9}$. Çalışmamızda, yoğun bakımda FQ kullanılan hastalarda, malignite varlığı, re-entübasyon uygulamaları, ViP gelişimi ve 7 günden uzun süreli florokinolon kullanımı olmak üzere mortalite ile ilişkili dört bağımsız risk faktörü saptanmıştır. Alvarez-Lerma ve arkadaşlarının ${ }^{27}$ yapmış olduğu çalışmada ise, yoğun bakımda levofloksasin veya levofloksasin ile kombine antibiyotik kullanılan hastalarda mortaliteyle ilişkili risk faktörleri, kombine antibiyotik tedavisi (OR 3.07; \%95 $\mathrm{Cl}$ 1.23-7.65), septik şok (OR 3.49; \%95 Cl 1.30-9.39) ve tedavi başarısızlığı (OR 32.6; \%95 Cl 13.5-78.9) olarak tanımlanmıştır. Çalışmamızın en önemli kısıtlamaları; tek merkezli olması, retrospektif yapılması ve hasta sayısının az olmasıdır.

Sonuç olarak bu çalışmada; solunumsal YBÜ'ye yatırılan hastalarda, FQ kullanımıyla MRSA enfeksiyonu gelişimi arasında istatistiksel olarak anlamlı olmamakla birlikte, pozitif bir korelasyon olduğu gözlenmiştir. FQ kullanılan hastalarda, yatıştaki yüksek lökosit düzeyleri ile hastane kaynaklı MRSA enfeksiyonu gelişimi arasında anlamlı bir ilişki bulunmuş; ayrıca, yedi günü aşan FQ kullanımının mortaliteyi artırdığı gösterilmiştir. YBÜ'de florokinolon başlanan hastalarda, başvuru lökosit düzeylerinin hastane enfeksiyonlarını öngörmede basit ve ucuz bir belirteç olarak kullanılabileceği ve FQ kullanım süresinin bir haftayı aşmaması gerektiği sonucuna varılmıştır. Bu sonuçların desteklenmesi için daha geniş kapsamlı ve prospektif çalışmalara gereksinim olduğu açıktır.

\section{KAYNAKLAR}

1. Hidron Al, Edwards JR, Patel J, et al. NHSN annual update: antimicrobial-resistant pathogens associated with healthcare-associated infections: annual summary of data reported to the National Healthcare Safety Network at the Centers for Disease Control and Prevention, 2006-2007. Infect Control Hosp Epidemiol 2008; 29(11): 996-1011.

2. Vincent JL, Rello J, Marshall J, et al. International study of the prevalence and outcomes of infection in intensive care units. JAMA 2009; 302(21): 2323-9. 
3. Safdar N, Maki DG. The commonality of risk factors for nosocomial colonization and infection with antimicrobial-resistant Staphylococcus aureus, enterococcus, gram-negative bacilli, Clostridium difficile, and Candida. Ann Intern Med 2002; 136(11): 834-44.

4. Park SY, Kang Cl, Joo EJ, et al. Risk factors for multidrug resistance in nosocomial bacteremia caused by extended-spectrum $\beta$-lactamase-producing Escherichia coli and Klebsiella pneumoniae. Microb Drug Resist 2012; 18(5): 518-24.

5. Naimi TS, LeDell KH, Como-Sabetti K, et al. Comparison of community- and health care-associated methicillin-resistant Staphylococcus aureus infection. JAMA 2003; 290(22): 2976-84.

6. Trouillet JL, Vuagnat A, Comparison of episodes due to piperacillin-resistant versus piperacillin-susceptible organisms. Clin Infect Dis 2002; 34(8): 1047-54.

7. Tam VH, Louie A, Fritsche TR, et al. Impact of drug-exposure intensity and duration of therapy on the emergence of Staphylococcus aureus resistance to a quinolone antimicrobial. J Infect Dis 2007; 195(12): 1818-27.

8. Weinstein RA. Epidemiology and control of nosocomial infections in adult intensive care units. Am J Med 1991; 91(3): 179-84.

9. Baudel JL, Tankovic J, Carrat F, et al. Does nonadherence to local recommendations for empirical antibiotic therapy on admission to the intensive care unit have an impact on in-hospital mortality? Ther Clin Risk Manag 2009; 5(3): 491-8.

10. Hill DA, Herford T, Parratt D. Antibiotic usage and methicillin-resistant Staphylococcus aureus: an analysis. J Antimicrob Chemother 1998; 42(5): 676-7.

11. Diekema DJ, Pfaller MA, Schmitz FJ, et al. Survey of infections due to Staphylococcus species: frequency of occurence and antimicrobiol susuceptibility of isolates collected in the United States, Canada, Latin America, Europa and the Western Pacific region for the SENTRY Antimicrobiol Surveillance Program, 1997-1999. Clin Infect Dis 2001; 32(Suppl 2): 114-32.

12. Melo EC, Fortaleza CM. Case-case-control study of risk factors for nasopharyngeal colonization with methicillin-resistant Staphylococcus aureus in a medical-surgical intensive care unit. Braz J Infect Dis 2009; 13(6): 398-402.

13. Nseir S, Di Pompeo C, Soubrier S, et al. First-generation fluoroquinolone use and subsequent emergence of multiple drug-resistant bacteria in the intensive care unit. Crit Care Med 2005; 33(2): 283-9.

14. Lafaurie M, Porcher R, Donay JL, Touratier S, Molina JM. Reduction of fluoroquinolone use is associated with a decrease in methicillin-resistant Staphylococcus aureus and fluoroquinolone resistant Pseudomonas aeruginosa isolation rates: a 10 year study. J Antimicrob Chemother 2012; 67(4): 1010-5.

15. Schneider-Lindner V, Delaney JA, Dial S, Dascal A, Suissa S. Antimicrobial drugs and community-acquired methicillin-resistant Staphylococcus aureus, United Kingdom. Emerg Infect Dis 2007; 13(7): 994-1000.

16. Hisamuddin NA, Azlan K. The use of laboratory and physiological parameters in predicting mortality in sepsis induced hypotension and septic shock patients attending the emergency department. Med J Malaysia 2012; 67(3): 259-64.

17. Yu CW, Juan LI, Wu MH, Shen CJ, Wu JY, Lee CC. Systematic review and meta-analysis of the diagnostic accuracy of procalcitonin, C-reactive protein and white blood cell count for suspected acute appendicitis. $\mathrm{Br}$ J Surg 2013; 100(3): 322-9.

18. Hotchkiss RS, Karl IE. The pathophysiology and treatment of sepsis. N Engl J Med 2003; 348(2): 138-50.

19. Hoser GA, Skirecki T, Złotorowicz M, Zielinska-Borkowska U, Kawiak J. Absolute counts of peripheral blood leukocyte subpopulations in intraabdominal sepsis and pneumonia-derived sepsis: a pilot study. Folia Histochem Cytobiol 2012; 50(3): 420-6.

20. Miedzybrodzki R, Fortuna W, Weber-Dabrowska B, Górski A. A retrospective analysis of changes in inflammatory markers in patients treated with bacterial viruses. Clin Exp Med 2009; 9(4): 303-12.

21. Matsumoto Y, Adjei AA, Yamauchi K, et al. A mixture of nucleosides and nucleotides increases bone marrow cell and peripheral neutrophil number in mice infected with methicillin-resistant Staphylococcus aureus. J Nutr 1995; 125(4): 817-22. 
22. Schmidt $H$, Bastholt $L$, Geertsen $P$, et al. Elevated neutrophil and monocyte counts in peripheral blood are associated with poor survival in patients with metastatic melanoma: a prognostic model. Br J Cancer 2005; 93(3): 273-8.

23. Leitch EF, Chakrabarti M, Crozier JE, et al. Comparison of the prognostic value of selected markers of the systemic inflammatory response in patients with colorectal cancer. Br J Cancer 2007; 97(9): 1266-70.

24. Cağatay AA, Ozcan PE, Gulec L, et al. Risk factors for mortality of nosocomial bacteraemia in intensive care units. Med Princ Pract 2007; 16(3): 187-92.

25. Shorr AF. Epidemiology of staphylococcal resistance. Clin Infect Dis 2007; 45 (Suppl 3): 171-6.

26. Warren DK, Guth RM, Coopersmith CM, Merz LR, Zack JE, Fraser VJ. Epidemiology of methicillin-resistant Staphylococcus aureus colonization in a surgical intensive care unit. Infect Control Hosp Epidemiol 2006; 27(10): 1032-40.

27. Alvarez-Lerma F, Palomar M, Olaechea P, León C, Sanchez M, Bermejo B; Study Group on Levofloxacin Use in the ICU. Levofloxacin in the treatment of pneumonia in intensive care unit patients. J Chemother 2004; 16(6): 549-56. 